\title{
INFORMATION SYSTEM IN BLOOD CENTER: FIRST STEP FOR THE VIRAL SAFETY
}

\author{
Kamal Tashtemirov, Sagit Imangazinov, Olga Tashtemirova, Semey State Medical University, \\ surgery1986@mail.ru
}

In the last decade, a special focus has been paid to blood donation system. This is due to two key factors: decline in the number of donors and rising amount of infectious diseases incidence, which increase cost of donated blood procurement. According to WHO recommendations, one of the factors that will improve viral safety of donated blood is information space, which includes medical facilities and blood centers. We have analyzed information flows in Pavlodar Region Blood Center in order to formalize them for creation of an information system model.

JEL Classification Number: I15, DOI: 10.12955/cbup.2013.49

Keywords: healthcare information system, donation, blood bank

\section{Introduction}

As Fauci (2003) wrote, in the last 5 years the national average risk of detecting markers of viral infections in donated blood were decreased and it indicates the beginning of transition to quality assurance system in blood transfusion service (Fauci, 2003). However, quantitative assessment of viral safety provision shows a significant lag of the domestic system from those of developed countries. According to WHO reports, risk of viral markers detection in donor serum in the US and EU countries is still 200 - 1000 times lower than in Kazakhstan. Residual risk of viral infections detection in donor plasma is approximately 1:100, while in developed countries this rate does not exceed 1:1000000 (WHO, 2001; WHO, 2003). Lopez (2006) determined that reasons of increased potential risk in fresh frozen plasma are in conventional national system for collection, storage and control of viral infections markers in blood and its components. As Dobroselsky and others wrote, introduction of information systems in the production of blood components can significantly reduce blood infection risk (Dobroselsky \& Zagoruiko, 2006; Dobroselsky, 1997).

A number of social and economic factors have led to a sharp deterioration of blood service in Kazakhstan. There is a general decrease in the number of donors, amount, quality and safety of blood components, breach of vertical structure of management and control of blood transfusion services. To overcome the existing negative situation in blood transfusion service, the Ministry of Public Health of the Republic of Kazakhstan has adopted "Blood Service Development Concept in Kazakhstan for 2011-2015". One of the points hereof is creation of a common information space between blood services in the country. 


\section{Current system analysis}

Analysis of the existing organization model of Pavlodar Region Blood Center is based on the study of its source documents and reports. Also there has been an analysis of information flows in the Blood Center conducted in order to determine the key points of information system. The current information system is represented by a common information center (CIC), the structure of which only includes a donor database (DB), the key point of which is donor's name. This database provides registration of donor's passport details, blood type, blood donations and medical contraindications. Exchange of information with other medical facilities is only performed upon receipt of reports from a number of medical facilities on positive results of test for transmissible infections and check with the existing database. Thus there is no possibility for data input and creation of a complete database for screening patients at the stage of patient's registration. Implementation and application of a single modern dataprocessing system shall provide automation of blood service institutions and organizations' activity.

\section{Description of existing processes}

There is only one purpose for creating information system in blood service to improve safety and quality of blood transfusion. As tasks, they include the following:

- information support and control preventing all kinds of human error in the way "from vein to vein",

- ensure traceability from donor to recipient and vice-versa,

- creation of a common information space,

- higher information awareness of all transfusion cycle participants, which allows organization of better planning, allocation and selection of blood components, analysis of results and complications and carrying out of research.

CIS is designed for complex informatization of procurement, examination, storage and allocation of blood and blood components, which will greatly improve safety and efficiency of production, introduce additional levels of quality control and provide significant and timely management of information.

Subsequent integration with information systems of regional blood centers and National Blood Center in a single information system will allow for:

- control of procedures for blood components production, solution of problems in planning and allocation of blood transfusion media among medical institutions, conduction of expert analysis of blood service institutions and organizations, identify problems and suggest solutions, and, ultimately, significantly raise the level of products' safety;

- creation common database of donors and those excluded from donation will provide an exception from possible donations from individuals excluded from donation already at the stage of address, regardless of their place of residence;

- the developed application software will provide automation of procurement, processing and allocation of blood and blood components, where the first point is the creation and using the standards in blood service organization and on the other point is assuring absolute accuracy of information; 
- the developed software based on the created functional model of national information center will provide processing of regional information flows and formation of common national databases.

The main tasks of CIS:

- to organize exchange and processing of data from excluded sources in the region (AIDS Center, CDC, tuberculosis center, etc.);

- to organize exchange and processing of blood transfusion data between blood centers and other medical facilities;

- to collect data and keep the common regional base of products, defects, requests from health facilities, distribution of transfusion media, transfusion protocols and recipients;

- to collect data and keep the common regional base of donors and those excluded from donation;

- to prepare exchange of database replications, results of donated blood examination and changes in the database of CIC, process of requests and respond to them, create electronic documents for issue of blood components;

- preparation and organization of data exchange with National Information Center.

Thus, data exchange system shall perform tasks of organization and exchange of data in accordance with the adopted rules and process them accordingly with the business rules.

At the national level, data exchange is provided between National Information Center and every regional information center as well as with government agencies, and at the regional level there is an exchange between Regional Information Center and every blood service organization.

Common information space development and implementation will enable all levels of government to:

- have data and control traffic of transfusion media correct to a unit of output;

- control range and quantities of transfusion media and on this basis to manage these stocks;

- in case of emergency provide individual selection of blood components from those available in a specific region or in Kazakhstan;

- in case of emergency to organize search for transfusion media in the nearby regions.

After analysis of the existing data flows we have decided to split the information system into several stages.

The first stage shall ensure availability of personal stations in all subdivisions of blood center.

In the second stage a prototype of information system shall be created. It contains a complete electronic file of donors, results of their examination before the procedure, results of visits, medical exemptions file, records of all laboratory tests (hematologic, biochemical, immunohematologic, serologic ones), data about any produced or obtained products from the time of conducted blood donation procedure to the time of issuing to medical and preventive facilities.

In the third stage, an optimization of information system shall be performed. The optimization includes data synchronization with other medical facilities of the region by optimizing data about donor on the basis of individual identification number (IIN). Then data on infectious diseases, results 
of laboratory tests and medical conditions which are contraindications to donation will be imported. CIS data will serve as a basis for obligatory initial check of donor for exclusion and control of intervals between procedures.

The main flow of information will include data about donor (formed in registration department) and marking details of blood container (formed in sampling department and modified in control laboratory, endpoint control and storage departments). In control department there are various methods applied for processing of source component (filtering, inactivation, etc.).

There is an additional information flow between the laboratory and control department which contains data of laboratory test results. By forming an information flow in the registration department, a request to CIC shall be made and modified data about donor are sent to CIC. A special task is to ensure control of information flows in the department of issue, as it is one of the main sectors providing transfusion safety of blood components. Formation of information flow including expiration date control before issue in medical facilities, reports on stocks and use of products are carried out in the department of issue.

The organizing basis of a blood service in the region can be a regional information center of regional blood center, and the main link to consolidate and manage data flow of the whole region may be a common information center (CIC).

CIC databases must contain information obtained from regional blood transfusion stations and subdivisions and plasma centers about donors and persons excluded from donation, examination of donor's blood, persons temporally excluded from donation, products, stocks of components and blood products under quarantine and in erythrocyte long-term storage department, components on dispatch, requests from medical facilities, issued products, transfusion reports and data on recipients, information on patients and carriers of blood-borne infections coming from epidemiological and venerological services, AIDS center, tuberculosis center, etc.

\section{Conclusion}

Our research suggests creation of an efficient system of information support for blood services in the country in accordance with applicable local and international laws. Application of information systems at all stages of blood service will optimize its performance and increase safety of blood components.

\section{References}

Dobroselsky, V. V. \& Zagoruiko, I. N. (2006). Avtomatizirovannaya informatsionnaya sistema perelivaniya na odnom kompyutere [Automated Transfusion Information System on one Computer]. Vestnik sluzhby krovi v Rossii [Bulletin of Blood Service in Russia], No.1, 29-35.

Dobroselsky, V. V. (1997). Osnovakh administrirovaniya informatsionnoy sistemy [Principles of Administration Information System]. Vestnik sluzhby krovi v Rossii [Bulletin of Blood Service in Russia], No.1, 20-21.

Fauci, A. S. (2003). Infectious Diseases: Considerations for the 21st Century. Clinical Infectious Diseases, 32, 675-85. 
Lopez, A. D. (2006). Global and Regional Burden of Disease and Risk Factors, 2001: Systematic Analysis of Population Health Data. The Lancet, 367, 1747-1757.

WHO Commission on Macroeconomics and Health. (2001). Macroeconomics and Health: Investing in Health for Economic Development. Geneva, Switzerland: WHO. Retrieved March 10, 2013, from http://whqlibdoc.who.int/publications/2001/924154550x.pdf

WHO. (2005). The World Health Report 2004. Geneva, Switzerland: WHO. Retrieved March 21, 2013 from http://www.who.int/whr/2004/en/report04_en.pdf 